\title{
"Enlarging the space of the possible"1 around what it means to educate and be educated
}

DEBORAH OSBERG, Editor-in-Chief

University of Exeter (UK)

Through this peer-reviewed journal we hope to contribute to an enlarging of the space of the possible around what it means to educate and to be educated.

To this end, we acknowledge that the tools and expectations of traditional academic discourse might have to be challenged on occasion. A prominent theme across the current complexity science literatures is that the linear narrative and the Euclidean image are inadequate to depict the emergence and the behavior of a complex form. Rather, instances of complex emergence call for webbed, multithreaded tales and nested, scale independent geometries to accommodate forms that can become more intricate, more dense, more pregnant with possibilities.

(Davis and Phelps, 2004, p.4)

\footnotetext{
${ }^{1}$ An early use of this phrase in the complexity and education community occurs in Sumara and Davis, 1997.
} 


\section{Opening conversation}

In this special issue of Complicity we depart from our usual journal format (refereed articles, invited semantic plays, vignettes, etc.) to present one refereed full paper and seven unrefereed (but edited) responses to it. In writing this editorial I have also departed from my usual script, as editor, by not directly addressing the topic of this special issue: Ton Jörg's "programmatic view" of complex educational reality. This is addressed, instead, in an afterword by Bill Doll (this issue, p. 72). Rather than engaging with this topic directly in this editorial, I wish to discuss our (editors) motivation for presenting a special issue in this format.

As Ton has produced a "programmatic view" of education and learning - i.e., a particular representation of complex educational reality - the question arises as to what should be done about it. Is such a view merely to be presented to our readers (perhaps together with other "competing" views) to either accept or reject as they see fit? Or is something more expected of a journal of this nature, which claims to address the complex open-endedness of our world and our conceptions of it? As the editor of Complicity one of my chief concerns as I grapple with the possible meanings of the task of editing a journal of complexity, is how the ethos of this journal can somehow reflect its topic. I believe it should be open-ended, it should be about "enlarging the space of the possible around what it means to educate and be educated." These are not my words. They are the words of founding co-editors Brent Davis and Renata Phelps in their first editorial piece for Complicity (December, 2004, p. 4, my emphasis) where they described their vision for the potential of this journal. In that piece they also explained that, since this journal deals with issues of complexity, the achievement of their envisioned goal implies that "the tools and expectations of traditional academic discourse might have to be challenged on occasion"(Ibid., my emphasis). It is these two statements that I wish to explore in this editorial as they relate very much to our (editors) motivation for presenting this special issue of Complicity in the "conversational" (as opposed to representational) format we have.

My analysis, I hope, may go some way toward explaining how a "conversational" structure of this special issue of Complicity challenges the tools and expectations of traditional academic discourse in a way that opens a space for academic innovation (enlarging the space of the possible) around what it means to educate and be educated. Let me begin with Davis and Phelps's comments about the tools and expectations of "traditional" academic discourse. I will then go on to discuss various meanings of the term "enlarging the space of the possible."

\section{The tools and expectations of traditional academic discourse}

For the most part "traditional academic discourse" uses the linear narrative and the Euclidean image to represent and communicate its findings and observations. These forms of representation are the familiar "tools of the trade" and any deviations from this 
style of discourse are often not recognized as "academic." However, as Davis and Phelps point out:

A prominent theme across the current complexity science literatures is that the linear narrative and the Euclidean image are inadequate to depict the emergence and the behavior of a complex form. Rather, instances of complex emergence call for webbed, multithreaded tales and nested, scale independent geometries to accommodate forms that can become more intricate, more dense, more pregnant with possibilities. (2004, p. $4)$.

By drawing attention to this point Davis and Phelps (if I interpret them correctly) are not implying that the journal should no longer accommodate articles that attempt to represent complex educational issues in a more traditional linear style. Many of the most well thought out and rigorous articles portray these complex issues in a highly linear style and such articles have made and continue to make valuable and important contributions to this journal and the field. They imply, rather, that it is necessary for the journal to provide additional space to accommodate non-linear and non-Euclidean forms of representation. Indeed the journal, since its inception in 2004, has made room for "non-traditional" contributions in all its sections. As well as the Semantic Play and Vignettes section, which are designed specifically to accommodate less traditional pieces, the editors ensure that refereed articles get the attention of "like minded" referees. In this sense Complicity can be understood to have "enlarged the space of the possible about what it means to educate and be educated." But this by no means exhausts the possible meanings of this phrase "enlarging the space of the possible." Nor does it do justice to Davis and Phelp's hopes for the journal.

\section{Enlarging the space of the possible}

Other understandings of the term "enlarging the space of the possible" come into view when we bear in mind that complexity not only poses a challenge to traditional (linear and Euclidean) forms of representation but also poses a challenge to the idea that knowledge is necessarily representational (see Cilliers, 1998; Osberg and Biesta, 2007, Osberg, Biesta and Cilliers, 2008). This latter challenge has deep implications for academic discourse which, for the most part, is based on a representational epistemology ${ }^{2}$ and is organized as a representational practice (rather than, e.g., an ethical, political or conversational practice).

When we understand academic discourse as a representational practice guided by a representational epistemology this leads us to believe that the knowledge (representations of reality) produced by the academic community must be re-presented as knowledge (representations of reality) to the academic community in order that their worth (as "better" or "worse" representations of reality) may be evaluated by this critical community. Depending on their uptake by the community, certain representations of

\footnotetext{
${ }^{2}$ I use the term "representational epistemology" when knowledge is understood to represent or "stand for" aspects of a reality that is somehow separate from the knowledge "itself." This applies regardless of whether knowledge is understood as a "picture" or a "construction" of reality.
} 
reality then become part of "knowledge" - they get cited, reproduced in other academic representations, and so on and in this way "add to," "expand," or "broaden" the knowledge of the community - while others fall by the wayside. In this sense, our knowledge of education can be understood to be "growing" in particular ways as it builds on, is informed by or adds to prior knowledge. With this representational understanding of academic discourse, Davis and Phelps's phrase "enlarging the space of the possible around what it means to educate and be educated" can be linked with the idea of the incremental growth of knowledge and hence with the idea of linear progress. This, however, not only sits uncomfortably with the non-linear "logic" of complexity, but is also problematic in that it puts the academic community in the position of having to make judgments about which or whose knowledge is worthy of being used to feed the ever-growing "body of knowledge" and whose is not. In an academic climate which increasingly understands knowledge representations as culturally situated this puts academics in a difficult position. If such judgments are made academics open themselves to accusations of academic elitism. If such judgments are not made, academics open themselves to accusations of "anything goes" relativism (for an elaboration on this theme, see Osberg, Doll and Trueit, 2008). It would seem there is a real need to understand the concept of "the growth of knowledge" in a non-linear sense.

But how do we understand the "growth of knowledge" in a non-linear sense? And can we achieve this through academic discourse (i.e., the sort of discourse with which we expect to engage when reading Complicity)? Is it possible to contrast such non-linear academic "enlargements" with other, more "traditional" understandings of academic progress - namely the linear variety - where the growth of knowledge is understood in terms of an orderly progression through increasingly "improved" occurrences of knowledge? I would like, at this point, to draw attention to what could be called an "emergentist" or "deconstructionist" ${ }^{\prime \prime}$ interpretation of "enlarging the space of the possible."

\section{Entering the space of the impossible}

An emergentist or deconstructionist understanding of "enlarging the space of the possible" can be understood as an exploration or movement into that which cannot currently be conceived as a possibility. If we can already imagine what is possible, achieving such is no longer enlarging the space of the possible, for it already exists in our minds. We are simply exploring different options within the space of the already possible. To enlarge the space of the possible it is necessary to enter and explore what might be called the space of "the impossible" (that which cannot currently be conceived as a possibility) or, as Derrida might put it, to experience and experiment with the possibility of the impossible (see, e.g., Derrida, 1992). But how, one might ask, is it possible to experience the impossible if not through one's imagination?

\footnotetext{
${ }^{3}$ After some ideas developed by Jacques Derrida under the name of "deconstruction." Elsewhere I link the "logic of emergence" quite closely to Derrida's deconstructionist logic (see, e.g., Osberg and Biesta, 2007).
} 
Certainly, when we are thinking with the linear logic of cause and effect, it is not possible to enter such a space (see Osberg and Biesta, 2007). With cause and effect thinking we understand the world in a mechanical sense where everything is made up of isolated parts and their rules of interaction and there is only a single way for the process to "unfold". With such an understanding of the world, simply knowing about parts and their rules of interaction enables us to project both forwards and backwards in time to calculate all possibilities which already exist as rational facts. Since, with linear thinking we already know (or can calculate) in advance what is possible before it has taken place, there is no route to the impossible (that which cannot be conceived as a possibility) and therefore no room to enlarge the space of the possible. The idea of "enlarging the space of the possible" remains logically impossible for we can think only within an economy of the same. This is not so when we are thinking with the non-linear or "emergentist logic."

With complexity thinking (or "thinking in complexity" as Ton Jörg and Klaus Mainzer describe it in this special issue) we understand the world in a more organic sense: in terms of dynamic interaction and emergence, or dynamically interacting "parts" and emergent "effects," if you will. Since dynamically interacting "parts" may produce emergent "effects" which cannot be accounted for (calculated in advance) by even the most exhaustive knowledge of the prior "stages" from which such effects arose (see e.g., Kim, 1999) it becomes logically possible, with this form of thinking, to escape the domain of the already possible and "think outside the box," so to speak. It is not just that dynamically interacting parts do not add up, but that they add up to more $e^{4}$. This means when emergence takes place, we enter the space of the impossible or incalculable. That is, we move into the space of that which cannot currently be conceived as a possibility: we enlarge the space of the possible. By this account, the "key" to enlarging the space of the possible (or entering the space of the impossible) is therefore dynamic interaction. Without dynamic interaction the idea of "entering the space of the impossible" remains logically impossible - closed - and hence we are unable to enlarge the space of the possible, unable to think outside an economy of the same. What does this mean in relation to academic discourse?

\section{Linear and non-linear academic discourse}

To put it most simply, when we think of academic discourse in a linear sense, we are tied to the idea that the (academic) ideas we are working with must make sense (or "add up"), they must fit together with each other and with our prior knowledge so that we can understand the importance of that with which we are engaging, calculate (already know in advance and make judgments about) what is possible before it has taken place. Academic discourse in the linear tradition can therefore be understood to operate within an economy of the same. The whole structure relies on the idea of "common ground," and "rules of the game" and necessarily occupies the space of the "already possible."

\footnotetext{
${ }^{4}$ To be sure, emergent "effects" may contain elements of what came before, but they also contain a "supplement" which is the incalculable part - the part that cannot be accounted for.
} 
Those operating outside the boundaries (rules of the game / common ground) can either be prevented from participating or, in a more politically correct academic environment (such as Complicity, which acknowledges the legitimacy of alternative conceptions/rules/ground), allowed to speak alongside other voices. The problem, however, is that while such alternatives styles and rules of academic discourse may exist side by side (for example in Complicity) there is no compunction for researchers, theorists and practitioners of different stripes to engage with content that follows other rules or occupies other ground (other than one's own). As such, journals such as Complicity which attempt to publish "non-traditional" papers alongside more traditional content may appear to have no real focus, no coherence, or simply be lacking in rigor. With a linear understanding of academic discourse, as soon as we move out of an economy of the same, the problem of relativism insinuates itself. And so, even though opportunities to engage with other academic rules and ground may be present, it is difficult to see how this may contribute to enlarging the space of the possible in the sense of entering the space of the impossible.

When we think about academic discourse in dynamically relational terms, on the other hand, this problem of relativism goes away. With dynamically relational or nonlinear thinking, academic discourse can be understood to take place in a space of complex responsiveness which - as a space of responsiveness - is necessarily not a space of common ground (for it is not possible to respond to that which is identical with oneself, one can only respond to an other). This means academic discourse can be understood to take place where "otherness" - other ideas that are different from our own - create such a space. In this sense it is the plurality of the ideas that creates the "academic ground" in which it becomes possible to enlarge the space of the possible (enter the space of the impossible). When different ideas are put into dynamic relation (i.e., communication or conversation) with each other there is no longer any possibility that we know where this will take us. All we know is that in engaging with other ideas, with the multiplicity of ideas, we enter new spaces of possibility, spaces which were previously outside the realms of our imagination. Engaging with alternative knowledge always complicates the scene, unsettles our closures and calls us into further conversations as we attempt to reclose what was opened. A "conversational" academic discourse, in other words, is a continual opening of closures instead of a progressive closure (as we work towards common ground).

\section{Knowledge as conversation}

In preparation for writing this editorial piece in which I intended to address our (the editors) motivation for opening a topic for discussion (rather than presenting versions of a topic as independent representations) I carried out a Google search on the phrase "knowledge as conversation" as that, initially, was to be the title of this editorial piece. That search led me to a blog where I found a quote by David Weinberger (2005), whose work focuses on how the Internet is changing human relationships, communication, and society. I find Weinberger's words particularly apt as a description of the kind of 
academic community that might engage in a practice of exploring the space of the impossible. This community would do so through placing their knowledge in conversation.

There is a big difference between a relativistic world in which contrary beliefs assert themselves and a conversational world in which contrary beliefs talk with one another. In the relativistic world, we resign ourselves to the differences. In the conversational world, the differences talk. Even though neither side is going to "win" - conversation is the eternal fate of humankind - knowledge becomes the negotiation of beliefs in a shared world. What do we need to talk through? What can't we give up? What do we believe in common that seems so different? What should we just not talk about? These are the questions that now shape knowledge.

Knowledge is not the body of beliefs that needs no further discussion. Knowledge is the never ending conversation. And much of that conversation is precisely about what we can disagree about and still share a world. (David Weinberger, 2005)

In this special issue of Complicity, we have tried to open a discussion around a particular idea - Ton Jörg's "complex vision" for education. By presenting people's ideas and thoughts in this way - rather than as knowledge representations for the sake of representation, to be simply "accepted" or "rejected" by the academic community - we hope to have created a space of unsettlement which may function as an inspiration or a goad to further exploration, experiment and hopefully even more discussion. We want to open things out, extend the conversation, create the "never ending conversation" (Ibid.).

In this editorial, instead of providing a summary of the ideas presented by individual contributors at the outset - and in a sense judging them before they can speak - I leave you to read into them what you will and draw your own conclusions from their interweavings. Bill Doll, who has tirelessly worked to bring this special issue of Complicity to fruition, who was the primary inspiration behind the idea of a special issue in this format, and whose own work addresses, again and again, the theme of knowledge as a never ending conversation, provides a commentary in an Afterword at the end.

\section{References}

Cilliers, P. 1998. Complexity and Postmodernism. London: Routledge.

Davis, B. and Phelps, R. 2004. Complicity: An introduction and a welcome. Complicity 1(1): 1-7.

Derrida, J. 1990. Force of law: The mystical foundation of authority. Cardozo Law Review, 11(5-6), 9191045

Kim, J. 1999. Making Sense of Emergence, Philosophical studies, 95 3-36.

Osberg D.C and Biesta, G.J.J. 2007 Beyond presence: Epistemological and pedagogical implications of strong emergence. Interchange 38(1) 31-51

Osberg, D., Biesta, G.J.J., and Cilliers, P. 2008. From representation to emergence: Complexity's challenge to the epistemology of schooling. Educational Philosophy and Theory. 40(1): 213-227

Osberg, D.C.., Doll., W.E.Jr., and Trueit, D. 2008. Gatekeepers of a complex field? Complicity 5(1) iii-ix. 


\section{Editorial}

Sumara, D.J. \& Davis, B. 1997. “Enlarging the space of the possible: Complexity, complicity, and action research practices." In Action Research as a Living Practice (pp. 299-312), edited by T. Carson and D.J. Sumara, New York, Peter Lang.

Weinberger, D (2005). Knowledge as Conversation. http://www.hyperorg.com/blogger/mtarchive/004374.html

(C) Copyright 2009. The author, DEBORAH OSBERG assigns to the University of Alberta and other educational and non-profit institutions a non-exclusive license to use this document for personal use and in courses of instruction provided that the article is used in full and this copyright statement is reproduced. The author also grants a non-exclusive license to the University of Alberta to publish this document in full on the World Wide Web, and for the document to be published on mirrors on the World Wide Web. Any other usage is prohibited without the express permission of the authors. 